\title{
Effects of Physical Distancing to Control COVID-19 on Public Health, the Economy, and the Environment
}

\author{
Stephen C. Newbold ${ }^{1}$ (D) . David Finnoff ${ }^{1} \cdot$ Linda Thunström $^{1} \cdot$ Madison Ashworth $^{1}$. \\ Jason F. Shogren ${ }^{1}$
}

Accepted: 2 July 2020 / Published online: 4 August 2020

(c) Springer Nature B.V. 2020

\begin{abstract}
Physical distancing measures are important tools to control disease spread, especially in the absence of treatments and vaccines. While distancing measures can safeguard public health, they also can profoundly impact the economy and may have important indirect effects on the environment. The extent to which physical distancing measures should be applied therefore depends on the trade-offs between their health benefits and their economic costs. We develop an epidemiological-economic model to examine the optimal duration and intensity of physical distancing measures aimed to control the spread of COVID19. In an application to the United States, our model considers the trade-off between the lives saved by physical distancing - both directly from stemming the spread of the virus and indirectly from reductions in air pollution during the period of physical distancingand the short- and long-run economic costs that ensue from such measures. We examine the effect of air pollution co-benefits on the optimal physical distancing policy and conduct sensitivity analyses to gauge the influence of several key parameters and uncertain model assumptions. Using recent estimates of the association between airborne particulate matter and the virulence of COVID-19, we find that accounting for air pollution co-benefits can significantly increase the intensity and duration of the optimal physical distancing policy. To conclude, we broaden our discussion to consider the possibility of durable changes in peoples' behavior that could alter local markets, the global economy, and our relationship to nature for years to come.
\end{abstract}

Keywords COVID-19 $\cdot$ Air pollution $\cdot$ Co-benefits $\cdot$ Physical distancing $\cdot$ Social distancing $\cdot$ Optimal control

\section{Introduction}

In the initial months of the COVID-19 pandemic, most nations have attempted to control the spread of infections by reducing the rate of contacts between people who carry the virus and those who have not yet been exposed. The various methods to achieve such

Stephen C. Newbold

snewbold@uwyo.edu

1 Department of Economics, University of Wyoming, Laramie, WY, USA 
reductions in contacts are referred to generically as "physical distancing" measures-also known as "social distancing" or "spatial distancing" (Abel and McQueen 2020). While physical distancing can reduce the death toll of the pandemic, it also can impose large costs on society as exemplified by the sharp declines in GDP and employment in the months following the initiation of physical distancing measures in the United States (Sachs 2020; U.S. Department of Labor 2020). This suggests there could be substantial gains from properly calibrating the intensity and the timing of physical distancing restrictions.

In this study, we characterize the time path of physical distancing that minimizes total economic damages from controlling the COVID-19 epidemic in the United States, accounting for a potentially important category of environmental co-benefits. We develop an integrated epidemiological-economic model that includes a standard model of disease transmission, the monetized value of COVID-19 deaths averted and lives saved from exposure to air pollution, and the short- and long-run costs of physical distancing. The model includes the main features of the disease spread process and the economic trade-offs associated with broad-based physical distancing measures that represent the main approach to controlling the spread before a vaccine or effective treatments are available.

We expand the model used in on our earlier benefit-cost analysis of physical distancing in several ways (Thunström et al. 2020). First, we explicitly connect the intensity and timing of physical distancing to both lives saved from the infection and the income lost from reduced work hours and lowered productivity. Second, we incorporate the co-benefits of reduced mortality risks from declines in air pollution during the period of physical distancing. This extension is motivated by a striking side-effect of physical distancing, as indicated by visibly reduced levels of ambient air pollution in many areas around the world (IEA 2020; Venter et al. 2020). Globally, outdoor air pollution is responsible for around 4.2 million premature deaths per year (World Health Organization 2020a), and recent estimates for the U.S. range from around 50,000 to 250,000 premature deaths per year attributable mainly to $\mathrm{PM}_{2.5}$ (Burnett et al. 2018; Bowe et al. 2019; Goodkind et al. 2019). Adding an air pollution component to our model allows us to account for the lives saved from reductions in pollution emissions as a co-benefit from physical distancing measures whose primary purpose is to control the spread of infections. Third, we include a putative link between air pollution and the virulence of COVID-19. Several recent studies have attempted to identify an interaction effect between air pollution and COVID-19 transmissibility or case fatality ratios (Wu et al. 2020; Ogen 2020; Persico and Johnson 2020). Initial results of these studies suggest that airborne particulate matter could have a significant positive mediating influence on COVID-19 fatalities, so we use our model to explore the potential effect of this link on the optimal physical distancing policy.

Our study draws on a mature literature that integrates economics and epidemiology to examine a wide variety of infectious diseases in humans (e.g. Gersovitz and Hammer 2004; Rowthorn et al. 2009; Perrings et al. 2014; Fenichel et al. 2011; Gersovitz 2011; Fenichel 2013; Philipson 2016). We also add to a growing collection of recent studies that apply optimal control theory or computational dynamic optimization techniques to the COVID19 outbreak in particular (e.g. Acemoglu et al. 2020; Alvarez et al. 2020; Eichenbaum et al. 2020; Farboodi et al. 2020; Gonzalez-Eiras and Niepelt 2020; Kruse and Strack 2020; Piguillem and Shi 2020; Toxvaerd 2020). A comprehensive review of these studies would take us too far afield, so here we briefly describe several closely related studies to highlight points of comparison between our work and that of others in the literature.

Farboodi et al. (2020) develop a continuous-time optimal control model with a vaccine backstop and endogenous physical distancing by optimizing individuals. They show that without regulation, individuals choose a sub-optimal level of physical 
distancing, reducing economic activity too late to achieve the socially optimal level of disease suppression. The optimal policy is characterized by an initial rapid ramp-up and a long duration of an intermediate level of physical distancing until a vaccine is developed. The authors apply a calibrated version of the model to the COVID-19 epidemic in the United States, which shows that the optimal policy delays the peak of infections to buy time for a vaccine. Eichenbaum et al. (2020) examine macroeconomic impacts of pandemics by modeling the behavioral responses of individuals to the evolving tradeoff between consumption and health risks during an infectious disease outbreak. They assume that the risk of infection increases with consumption, which leads to a decline in both market demand and supply during a pandemic, resulting in an economic recession. Alvarez et al. (2020) and Kruse and Strack (2020) also study the optimal timing of physical distancing, accounting for both deaths due to infection and the economic costs of physical distancing, assuming that a vaccine or fully effective treatment will be developed within one year. In both cases, the optimal policy response allows infections to rise until they are close to the medical system capacity, and then physical distancing measures are rapidly implemented to keep the number of infections below the medical system's capacity constraint for a period of time that dampens or eliminates a second wave of infections. Acemoglu et al. (2020) include multiple risk groups in a pandemic control model, where the groups are characterized by differing interaction behaviors and by age, which affects their fatality risk if infected. The authors use the model to examine the effects of targeted lockdowns, and find that differentiated lockdown policies will outperform those that are uniformly applied to the whole population. Gonzalez-Eiras and Niepelt (2020) consider the implications of non-optimally timed physical distancing programs, and find that the net benefits of the policy can be drastially reduced if controls are initiated too early or kept in place too long. Toxvaerd (2020) characterizes the equilibrium (unregulated) behavior of individuals in a model of infectious disease spread with no risk of death but with reduced flow utility in the infected state and with a linear cost of physical distancing. The equilibrium path of physical distancing has the effect of flattening the curve of infections at a characteristic level of infections determined by a combination of epidemiological and economic parameters.

Our model differs in the details but shares many of the same basic features as those reviewed above, including a traditional epidemiological model of disease spread and a representation of the influence of physical distancing on deaths from the infection and economic output or income. Our main modeling innovation is to incorporate a link between physical distancing and air pollution, as well as the interaction between pollution and the COVID-19 fatality rate. To our knowledge, our study is the first to examine this link in an optimal control framework, which allows us to assess a potentially important category of co-benefits from physical distancing.

A final note before proceeding to the details of the model. We view our approach, like the studies described above, as closer to the "streamlined" than the "elaborated" end of the spectrum of possible models. We include the main features of the system relevant to our primary research questions, but otherwise we intentionally simplify as much as possible. We agree with Pindyck (2020) that calibrated SIR models applied to the COVID-19 outbreak should be viewed as only rough approximations to reality and taken with a grain of salt. At the same time, even if they cannot provide precise forecasts and definitive policy prescription, we believe that strategically simplified models roughly calibrated to the stylized facts can be useful for developing qualitative insights and for generating preliminary comparisons of alternative control scenarios. 


\section{Methods}

To project the number of infections and deaths under various physical distancing policies, we use a discrete-time SIR compartment model (Kermack and McKendrick 1927; Hethcote 1989). We modify the standard model to represent the influence of physical distancing on the contact rate and the endogeneity of the case fatality ratio as the health care system becomes overwhelmed by a surge of infected individuals seeking medical care. We include a link between physical distancing and mortality from air pollution, as well as an interaction between air pollution concentrations and the COVID-19 case fatality ratio. The shortand long-run economic costs of physical distancing depend on the average distancing fraction prior to the arrival of a vaccine and the assumed speed of economic recovery.

\subsection{Disease Dynamics}

The equations of motion for susceptible, infected, and recovered individuals are

$$
\begin{gathered}
S_{t+1}=S_{t}-\left(1-x_{t}\right)^{2} \beta S_{t} I_{t}, \\
I_{t+1}=I_{t}+\left(1-x_{t}\right)^{2} \beta S_{t} I_{t}-\gamma I_{t}-D_{t},
\end{gathered}
$$

and

$$
R_{t+1}=R_{t}+\gamma I_{t}
$$

In Eq. (1), $\beta$ is the contact rate without physical distancing, and $x_{t}$ is the fractional reduction in the number of potential transmission encounters that all individuals-both susceptible and infected-have in period $t$ (Alvarez et al. 2020). We refer to $x_{t}$ as the "distancing fraction," which will serve as the control variable in the regulator's optimal control problem.

In Eq. (2), $\gamma$ is the rate of recovery from infection (the reciprocal of the average duration that individuals remain infected and able to spread the virus), and $D_{t}$ is the number of deaths due to infection in period $t$. Denoting the case fatality ratio by $\rho_{t}$, the number of infected individuals who die in period $t$ is

$$
D_{t}=\gamma \frac{\rho_{t}}{1-\rho_{t}} I_{t}
$$

Note that $\rho_{t}$ is the probability of dying from the infection before recovering, not the per period probability of death for infected individuals (Keeling and Rohani 2011, p 34). We model the case fatality ratio as endogenous to the system, and indirectly responsive to the physical distancing policy through its influence on the evolution of infections. As the number of infected individuals requiring medical care increases, the health care system becomes stressed. This leads to infected individuals receiving a lower standard of care as scarce medical resources are spread ever more thinly. We represent this feedback by a logistic function of infections,

$$
\rho_{t}=\rho_{l o}+\frac{\rho_{h i}-\rho_{l o}}{1+e^{-k\left(I_{t}-\tilde{I}\right)}}
$$


where $\rho_{l o}$ is the lower-bound case fatality ratio, which will obtain when $I_{t}$ is much lower than a critical value of infections, $\tilde{I}$ (corresponding to the inflection point of the logistic function), and $\rho_{h i}$ is the upper-bound case fatality ratio, which will obtain when $I_{t}$ is much higher than $\tilde{I}$. The parameter $k$ controls the steepness of the logistic function, so for high $k$ the relationship approaches a step function with $\rho_{l o}$ for all $I_{t}<\tilde{I}$ and $\rho_{h i}$ for all $I_{t}>\tilde{I}$, as assumed in Thunström et al. (2020). We assume that recovery from infection yields immunity to the virus, although this has not been firmly established for COVID-19. While a number of studies find that people develop antibodies from the infection, the extent of protection from subsequent infections is still uncertain (World Health Organization 2020b).

Equations (1)-(5) comprise the modified SIR model with physical distancing and endogenous case fatality ratio. We use this model to project the number of infections and deaths under various physical distancing policies represented by the time path of the distancing fractions, $x_{t}$. The regulator's task is to find and enforce the sequence of $x_{t}$ 's that minimizes the total damage from the outbreak, which includes the value of lives lost due to infection, minus the value of lives saved due to reduced pollution, plus the value of current and future income lost due to the reduced economic activity associated with physical distancing.

\subsection{Lives Saved from Reduced Air Pollution}

We account for the value of lives saved from air pollution in the period of physical distancing due to lower emissions from reduced economic activity. To do so, we use a proportional hazard model (Cox 1972; Harrell 2015), which implies that the number of deaths averted in a time period due to a reduction in pollution concentration from $Z_{0}$ to $Z_{1}$ is

$$
\text { Lives saved }=M_{0}\left[1-e^{-\delta\left(Z_{0}-Z_{1}\right)}\right],
$$

where $M_{0}$ is the initial deaths from all causes in the time period, $Z_{0}$ is the initial level of air pollution, $Z_{1}$ is a lower level of pollution due to reduced economic activity caused by physical distancing, and $\delta$ is the air pollution hazard coefficient.

To compress notation in what follows, we define the fractional reduction in the average pollution concentration during the period of physical distancing as $z_{X}$, so $Z_{0}-Z_{1}=z_{X} Z_{0}$. Air pollution emissions increase with overall economic activity, with an especially strong link to activity in the transportation sector. To represent this linkage, we assume that air pollution emissions on day $t$ are a possibly non-linear function of the physical distancing fraction, $x_{t}$. Specifically, the fractional reduction in the average pollution concentration during the period of physical distancing is

$$
z_{X}=1-\frac{1}{T} \sum_{t=1}^{T}\left(1-x_{t}\right)^{\omega},
$$

where days are indexed by $t$, and $T$ is the duration of the physical distancing policy in days. The exponent $\omega$ controls the shape of the response of pollution to physical distancing. $\omega=1$ is the linear case, for which $z_{X}=\frac{1}{T} \sum_{t=1}^{T} x_{t}$, while $\omega<1(>1)$ implies a sub-linear (supra-linear) response of emissions to distancing, in which case the fractional reduction in pollution with physical distancing would be less than (greater than) the distancing fraction. To understand how a non-linear response could arise, suppose that the average individual's inter-personal contacts are evenly split between contacts with co-workers at the workplace and contacts with friends and neighbors close to home. Also suppose that commuting to and from work accounts for more (less) than half of the average individual's vehicle miles 
travelled and associated pollution emissions. If early increments of physical distancing mainly involve work-from-home policies, then, under the prior suppositions, the average person's inter-personal contacts would be reduced by half while her pollution emissions would be reduced by more (less) than half, which implies $\omega>(<) 1$. Here we use $\omega=1$, which we view as natural default assumption.

Several recent studies have examined possible links between air pollution and COVID19 related deaths. Long-term exposure to air pollution contributes to many of the underlying health conditions that put people at higher risk for severe consequences from COVID19 , particularly respiratory diseases. Such respiratory conditions also might be exacerbated by contemporaneous air pollution concentrations, which could compromise the body's ability to mount an effetive immune response to COVID-19. Focusing on the U.S., Wu et al. (2020) find that a $1 \mu \mathrm{g} \cdot \mathrm{m}^{-3}$ higher long-term average concentration of $\mathrm{PM}_{2.5}$ (between the years 2000-2016) is associated with an 8\% increase in the COVID-19 fatality risk. Other researchers have examined the possibility that airborne particulate matter (PM) facilitates the transmission of SARS-CoV-2 through the air (Martelletti and Martelletti 2020; di Toppi et al. 2020; Setti et al. 2020), which could increase force-of-infection for repiratory disease transmission (Tang et al. 2018). Persico and Johnson (2020) used the suspension of U.S. Environmental Protection Agency enforcement activities as a natural experiment to estimate the impact of short-run decreases in pollution on COVID-19 fatalities at the county level, and find large effects. To examine the potential importance of such a link for the optimal physical distancing policy, we include an interaction between air pollution and the COVID-19 case fatality ratio, which appears in Eq. (4) above. This allows us to compare the overall deaths from infection and lives saved from air pollution between otherwise equivalent model runs with and without the interaction included. When the interaction is included, the case fatality ratio in each period is adjusted by a factor that depends on the overall reduction in air pollution due to physical distancing, i.e.,

$$
\rho_{t}^{\prime}=\rho_{t} e^{-v z_{X} z_{0}}
$$

where $v$ is the air pollution-infection interaction coefficient.

\subsection{Valuing Lives}

To value lives saved from infection or air pollution, we use a central estimate of the "value per statistical life" (VSL). This quantity represents the average marginal willingness to pay for reducing the probability of death in a time period, i.e., the marginal rate of substitution between money and mortality risk (Viscusi 2018). ${ }^{1}$ Here we use a constant VSL, though some authors use age-adjusted VSL values, typically declining for older individuals (e.g. Greenstone and Nigam 2020), and others value the expected loss of life-years rather than expected deaths (e.g. Hall et al. 2020). Pindyck (2020) also suggests that a lower average VSL value should be used when the number of deaths averted is large, due to diminishing marginal willingness to pay for risk reductions. The influence of age on the VSL has been examined in a number of previous studies (e.g. Shepard and Zeckhauser 1984; Kniesner and Viscusi 2006; Evans and Smith 2006; Hammitt 2007), but no clear consensus on a

\footnotetext{
1 See Cameron (2010) for an extended discussion of the often-misunderstood term "value per statistial life," and see Simon et al. (2019) for an examination of alternative labels designed to be less prone to lead to confusion for non-economists.
} 
singular strategy to adjust for age has yet emerged in the literature. In the meantime, we follow U.S. federal agency recommendations and use a fixed central value of the VSL for all ages in our benchmark runs (U.S. Office of Management and Budget 2003; National Research Council 2008; U.S. Environmental Protection Agency 2014; U.S. Department of Transportation 2016).

\subsection{Cost of Physical Distancing}

The relationship between the extent of physical distancing and lost income in society is typically taken to be linear (e.g. Alvarez et al. 2020; Toxvaerd 2020; Kruse and Strack 2020; Piguillem and Shi 2020; Bolzoni et al. 2019; Hansen and Day 2011; Lee et al. 2010). Yet the possibility exists that the amount of income lost may be lower or higher than the physical distancing fraction. We introduce flexibility into the physical distancing cost function by allowing for non-constant returns to the rate of interpersonal contacts; specifically, we assume that per capita income on day $t$ is a possibly nonlinear function of contacts, i.e., $y_{t} \propto\left(1-x_{t}\right)^{\theta}$, where $\theta=1$ is the linear case and $\theta<1(>1)$ implies decreasing (increasing) returns, in which case the fraction of income lost with physical distancing would be less than (greater than) the distancing fraction. If mixing can be reduced initially by some people working remotely, traveling less, minimizing face-to-face meetings, etc., without being furloughed or losing their jobs, then $\theta$ would be less than 1 . Considering that some fraction of the workforce can reduce mixing with relatively little loss of productivity, we view $\theta=1$ as a conservative benchmark assumption.

We account for both the short-run and long-run cost of physical distancing. The shortrun cost is the present value of lost income during the period of physical distancing,

$$
v=\sum_{t=1}^{T} y\left[1-\left(1-x_{t}\right)^{\theta}\right] e^{-r^{\prime} t},
$$

where $y$ is aggregate income per day with no physical distancing, and $r^{\prime}$ is the daily discount rate. The long-run cost of physical distancing is the present value of lost income after the period of physical distancing, which will depend on the speed of economic recovery after the initial decline in aggregate income. To represent the long-run cost, we assume that income growth will be temporarily elevated as the economy recovers from the shock, and the post-outbreak growth path will asymptotically approach the counterfactual no-outbreak growth path at a constant rate $\varphi$. Based on these assumptions, and discounting future income at a constant rate $r$, the present value of lost income after the period of physical distancing is

$$
V=y_{X} Y_{0} \frac{e^{-r^{\prime} T}}{r+\varphi}
$$

where $y_{X}=1-\frac{1}{T} \sum_{t=1}^{T}\left(1-x_{t}\right)^{\theta}$ is the fractional loss of aggregate income during the period of physical distancing, $Y_{0}$ is aggregate annual income before the outbreak, and $r$ is the annual discount rate.

Combining the relevant elements specified above, the total damage function is

$$
T D=V S L \times\left[\sum_{t=0}^{T} D_{t}-M_{0}\left(1-e^{-\delta z_{X} Z_{0}}\right)\right]+v+V .
$$


Equation (11) combines the value of COVID-19 deaths, the value of averted air pollution deaths, and the value of lost income in the short-run and the long-run. Note that the control variables, $x_{t}$, are implicit in Eq. (11), through the definitions of $z_{X}, y_{X}, v$, and $V$, and through the dependence of the $D_{t}$ 's on the $x_{t}$ 's as determined by Eqs. (1)-(5).

\subsection{Model Calibration and Solution}

Following Thunström et al. (2020), we use $R_{0}=2.4$ (Liu et al. 2020; Ferguson et al. 2020; Aronson et al. 2020), $\gamma=1 / 6.5$ (Liu et al. 2020; Lauer et al. 2020), $\rho_{l o}=0.005$, and $\rho_{h i}=0.015$ (Riou et al. 2020; Wilson 2020; Yang et al. 2020; Dorigatti et al. 2020; Unwin et al. 2020). ${ }^{2}$ In a sensitivity analysis, we use $R_{0}=4.8$, which is closer to the more recent estimate reported by Sanche et al. (2020).

To specify the inflection point of the case fatality ratio function, $\tilde{I}$, we assume that if $5 \times 10^{5}$ hospital beds are occupied by COVID-19 patients-roughly half of the $9.24 \times 10^{5}$ staffed beds in U.S. hospitals (American Hospital Association 2020) - then the case fatality rate would be at the mid-point of its possible range between $\rho_{l o}$ and $\rho_{h i}$. Wu and McGoogan (2020) reported that 5\% of COVID-19 cases in China were "critical," so we assume that $5 \%$ of COVID-19 infections will require the use of a hospital bed. This gives $\tilde{I}=10^{6} \times 0.5 \div 0.05=10^{7}$ infected individuals. That is, if on any given day 10 million people are infected by the virus, then a fraction $\left(\rho_{l o}+\rho_{h i}\right) / 2$ would not be expected to survive. We set the steepness parameter, $k$, to give a pronounced S-shape but not a severe step function.

To calibrate the air pollution hazard coefficient, $\delta$, we rearrange the proportional hazard function in Eq. (6) to get $\delta=-Z_{0}^{-1} \ln \left(1-m_{0} / M_{0}\right)$, where $m_{0}$ is the baseline (pre-outbreak) number of deaths per year attributable to air pollution, and $M_{0}$ is the baseline number of deaths per year from all causes. Burnett et al. (2018) reported a population-weighted average $\mathrm{PM}_{2.5}$ concentration in the U.S. of $7.9 \mu \mathrm{g} \cdot \mathrm{m}^{-3}$. Goodkind et al. (2019) estimated that 107,000 premature deaths in the U.S. are attributable to $\mathrm{PM}_{2.5}$. Xu et al. (2018) reported an age-adjusted death rate of 723.6 in 100,000 in the U.S. in 2018. The U.S. population size was $3.27 \times 10^{8}$ in 2018 . Combining these figures in the calibration equation gives $\delta=5.85 \times 10^{-3}$.

In our benchmark model we do not include an interaction between air pollution and the COVID-19 case fatality ratio, so we set $v=0$. A causal link between these variables could have a profound impact on the optimal physical distancing policy, so we examine the implications of such a link in model variations using two preliminary estimates of this association. First, Persico and Johnson (2020) find that a short-run increase in $\mathrm{PM}_{2.5}$ of 1 $\mu \mathrm{g} \cdot \mathrm{m}^{-3}$ is associated with a doubling of the COVID-19 case fatality ratio, so in a "strong link" model variation we set $v=\ln (2)$. Second, Wu et al. (2020) find that differences in long-run average $\mathrm{PM}_{2.5}$ concentrations among U.S. counties of $1 \mu \mathrm{g} \cdot \mathrm{m}^{-3}$ is associated with an 8 percent increase in the COVID-19 case fatality ratio, so in a "weak link" model variation we set $v=\ln (1.08)$.

To quantify the benefits of lives saved, we use a benchmark VSL value of $\$ 10$ million. This is a central estimate from hedonic wage studies of the value per statistical life (Viscusi 2018; Kniesner and Viscusi 2019), and is consistent with U.S. federal agency benefit-cost

\footnotetext{
${ }^{2}$ Estimates of the case fatality ratio across states in the U.S. by the Imperial College COVID-19 Response Team range from roughly 0.005 to 0.013 (Unwin et al. 2020, Fig. 17).
} 
Table 1 Model parameter descriptions and values

\begin{tabular}{lll}
\hline Parameter & Description & Value(s) \\
\hline$R_{0}$ & Basic reproductive rate & $2.4,4.8$ \\
$\gamma$ & Rate of recovery from infection $\left[\mathrm{day}^{-1}\right]$ & $1 / 6.5$ \\
$\rho_{l o}$ & Case fatality ratio, lower bound & 0.005 \\
$\rho_{h i}$ & Case fatality ratio, upper bound & 0.015 \\
$\tilde{I}$ & Heath care system critical capacity & $10^{7}, 1.5 \cdot 10^{7}$ \\
$Z_{0}$ & Air pollution concentration $\left[\mu \mathrm{g} \cdot \mathrm{m}^{-3} \mathrm{PM}_{2.5}\right]$ & 7.9 \\
$\omega$ & Curvature of distancing pollution function & 1 \\
$\delta$ & Air pollution hazard coefficient & $5.85 \cdot 10^{-3}$ \\
$v$ & Air pollution-infection interaction & $0,0.0770,0.693$ \\
$\theta$ & Curvature of distancing cost function & $1,0.5$ \\
$\varphi$ & Economic recovery rate [year $\left.{ }^{-1}\right]$ & 0.300 \\
$r$ & Discount rate [year $\left.{ }^{-1}\right]$ & 0.03 \\
$V S L$ & Value per statistical life [US\$] & $10 \cdot 10^{6}, 4.5 \cdot 10^{6}$ \\
\hline
\end{tabular}

Entries with multiple values correspond to case variations shown in Figs. 1, 2, and 3 and Table 2. All other parameters are held at their benchmark values shown here

guidelines (U.S. Environmental Protection Agency 2014; U.S. Department of Transportation 2016). In a sensitivity analysis we use a lower value of $\$ 4.5$ million, which is consistent with the average age-varying VSL used by Greenstone and Nigam (2020) to monetize the impact of physical distancing in the U.S.

To specify $\varphi$, which controls the long-run costs of physical distancing, we make an assumption about the time required for aggregate income to recover to its counterfactual no-outbreak path. Specifically, we define the recovery time, $t_{R}$, as the time required for the gap between the actual GDP path and the no-outbreak path to shrink by $95 \%$, i.e., $e^{-\varphi t_{R}}=0.05$, so $\varphi=-t_{R}^{-1} \ln (0.05)$. We assume $t_{R}=10$ years, double the average recovery time among all bear markets since 1835 (Sachs 2020), which gives $\varphi=0.3 \mathrm{yr}^{-1}$.

Finally, to compute the present value of future income losses, we use a U.S. federal agency recommended discount rate of $r=0.03 \mathrm{yr}^{-1}$ (U.S. Office of Management and Budget 2003; U.S. Environmental Protection Agency 2014). Table 1 lists all model parameters and their benchmark and sensitivity case values.

To solve the model, we use a numerical policy iteration approach (Bertsekas 2015). First, we initialize the distancing fraction to zero for the entire time horizon, $x_{t}^{0}=0 \forall t$. Then we compute the gradient of the objective function $\left(g_{t}^{i}=\partial T D / \partial x_{t}^{i} \forall t\right)$, update the policy function $\left(x_{t}^{i+1} \leftarrow x_{t}^{i}+\Delta \times g_{t}^{i} \forall t\right.$, where $\Delta$ is a suitably small step size), and repeat for $i=1,2,3, \ldots, i_{\text {max }}$ iterations. For consistency and reproducibility we use $i_{\max }=10^{3}$, which appears to be sufficient to achieve convergence for all cases examined in this paper.

\section{Results}

We use the model to characterize the optimal timing and intensity of physical distancing to control the COVID-19 outbreak in the U.S., and to examine the influence of air pollution co-benefits on the optimal physical distancing policy. Considering the uncertainty surrounding many aspects of the system, our benchmark parameters described above and 

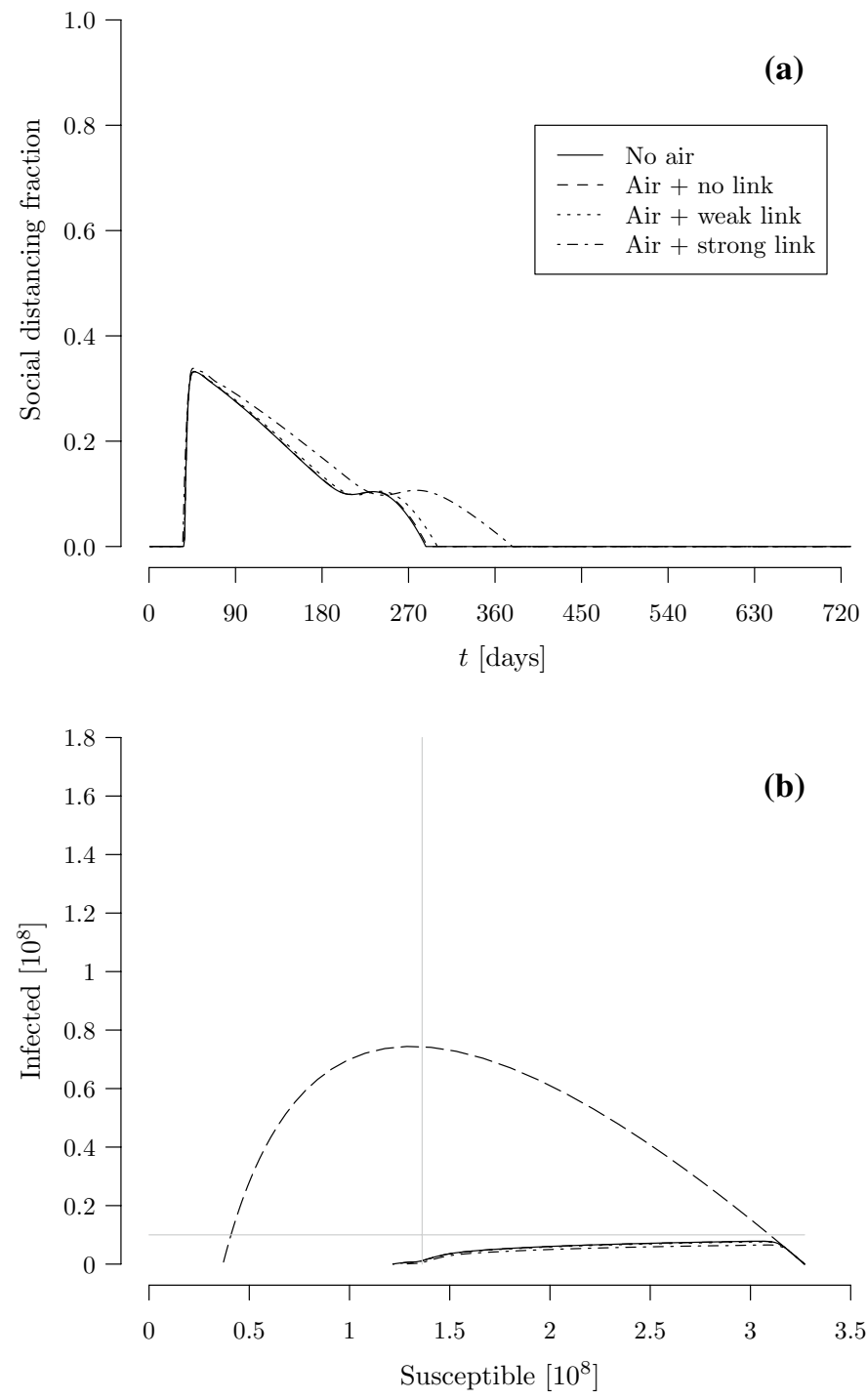

Fig. 1 Optimal control path (a) and $S-I$ phase diagram (b) given $R_{0}=2.4, V S L=10^{7}, \theta=1$, and $\tilde{I}=10^{7}$

shown in Table 1 are meant to serve mainly as a point of comparison for alternative cases. To maintain continuity with previous work, our benchmark parameters are largely consistent with Thunström et al. (2020), aside from the new model features.

Three key parameters that drive the model results are the basic reproduction number, $R_{0}$, the value per statistical life, VSL, and the curvature of the physical distancing cost function, $\theta$. Results for our benchmark case and two additional cases involving variations in one or two of these key parameters are presented in Figs. 1, 2, 3 and Table 2.

The graphs in Fig. 1 show results for our benchmark case, which uses our preferred central parameter values and most closely resembles our prior analysis (Thunström et al. 
Table 2 Parameter values and outcomes for three cases and four treatments of air pollution in the model: no air pollution effects, air pollution with no link to COVID-19 fatality, air pollution with a weak link to COVID-19 fatality, and air pollution with a strong link to COVID-19 fatality

\begin{tabular}{|c|c|c|c|}
\hline & 1 & 2 & 3 \\
\hline \multicolumn{4}{|l|}{ Parameters } \\
\hline$R_{0}$ & 2.4 & 2.4 & 4.8 \\
\hline$V S L\left[10^{6} \$\right]$ & 10 & 10 & 4.5 \\
\hline$\theta$ & 1 & 0.5 & 1 \\
\hline \multicolumn{4}{|l|}{ Outcomes } \\
\hline COVID-19 deaths, uncontrolled $\left[10^{6}\right]$ & 4.12 & 4.12 & 4.75 \\
\hline \multicolumn{4}{|l|}{ No air pollution } \\
\hline COVID-19 deaths averted $\left[10^{6}\right]$ & 2.47 & 2.65 & 1.17 \\
\hline Immediate GDP decline & 0.0595 & 0.0449 & 0.0290 \\
\hline Net benefits $\left[10^{12} \$\right]$ & 19.0 & 22.1 & 3.76 \\
\hline \multicolumn{4}{|l|}{ Air pollution no link } \\
\hline COVID-19 deaths averted $\left[10^{6}\right]$ & 2.47 & 2.65 & 1.17 \\
\hline Pollution deaths averted $\left[10^{3}\right]$ & 6.54 & 9.41 & 3.20 \\
\hline Immediate GDP decline & 0.0598 & 0.0457 & 0.0292 \\
\hline Net benefits $\left[10^{12} \$\right]$ & 19.0 & 22.2 & 2.45 \\
\hline \multicolumn{4}{|l|}{ Air pollution weak link } \\
\hline COVID-19 deaths averted $\left[10^{6}\right]$ & 2.55 & 2.79 & 1.31 \\
\hline Pollution deaths averted $\left[10^{3}\right]$ & 6.76 & 10.6 & 3.56 \\
\hline COVID-19xpollution deaths averted $\left[10^{3}\right]$ & 60.0 & 81.0 & 68.6 \\
\hline Immediate GDP decline & 0.0619 & 0.0514 & 0.0325 \\
\hline Net benefits $\left[10^{12} \$\right]$ & 19.6 & 23.0 & 2.75 \\
\hline \multicolumn{4}{|l|}{ Air pollution strong link } \\
\hline COVID-19 deaths averted $\left[10^{6}\right]$ & 3.11 & 3.57 & 2.60 \\
\hline Pollution deaths averted $\left[10^{3}\right]$ & 8.29 & 15.7 & 6.80 \\
\hline COVID-19xpollution deaths averted $\left[10^{3}\right]$ & 519 & 662 & 872 \\
\hline Immediate GDP decline & 0.0759 & 0.0760 & 0.0622 \\
\hline Net benefits $\left[10^{12} \$\right]$ & 23.9 & 28.5 & 5.70 \\
\hline
\end{tabular}

2020). In Fig. 1, panel (a) shows the daily progression of the optimal physical distancing policy, and panel (b) shows the associated $S-I$ phase diagram for the uncontrolled and optimally controlled scenarios, for each of four air pollution variations with all other parameters set at their benchmark values. ${ }^{3}$ The highest dashed curve in the phase diagram depicts the uncontrolled outbreak. The far right end of the curve corresponds to the start of the outbreak $\left(S_{0}, I_{0}\right)$. Moving from right to left, the curve traces out the $S-I$ pairs as the outbreak proceeds: $I_{t}$ increases to a maximum around 70 million individuals then declines back to zero, while $S_{t}$ declines monotonically as individuals are irreversibly removed from the susceptible compartment. At the end of the outbreak, $S_{t}$ has declined to around

\footnotetext{
3 We attempt to use the following nomenclature consistently in our presentation of results: "cases" refers to different sets of the three key parameters $\left(R_{0}, V S L, \theta\right)$ that distinguish our sensitivity analyses, "scenarios" refers to different social distancing policies within each case (in particular, the uncontrolled scenario where $x_{t}=0 \forall t$ and the optimal control scenario), and "variations" refers to different treatments of the air pollution co-benefits of physical distancing within each scenario.
} 

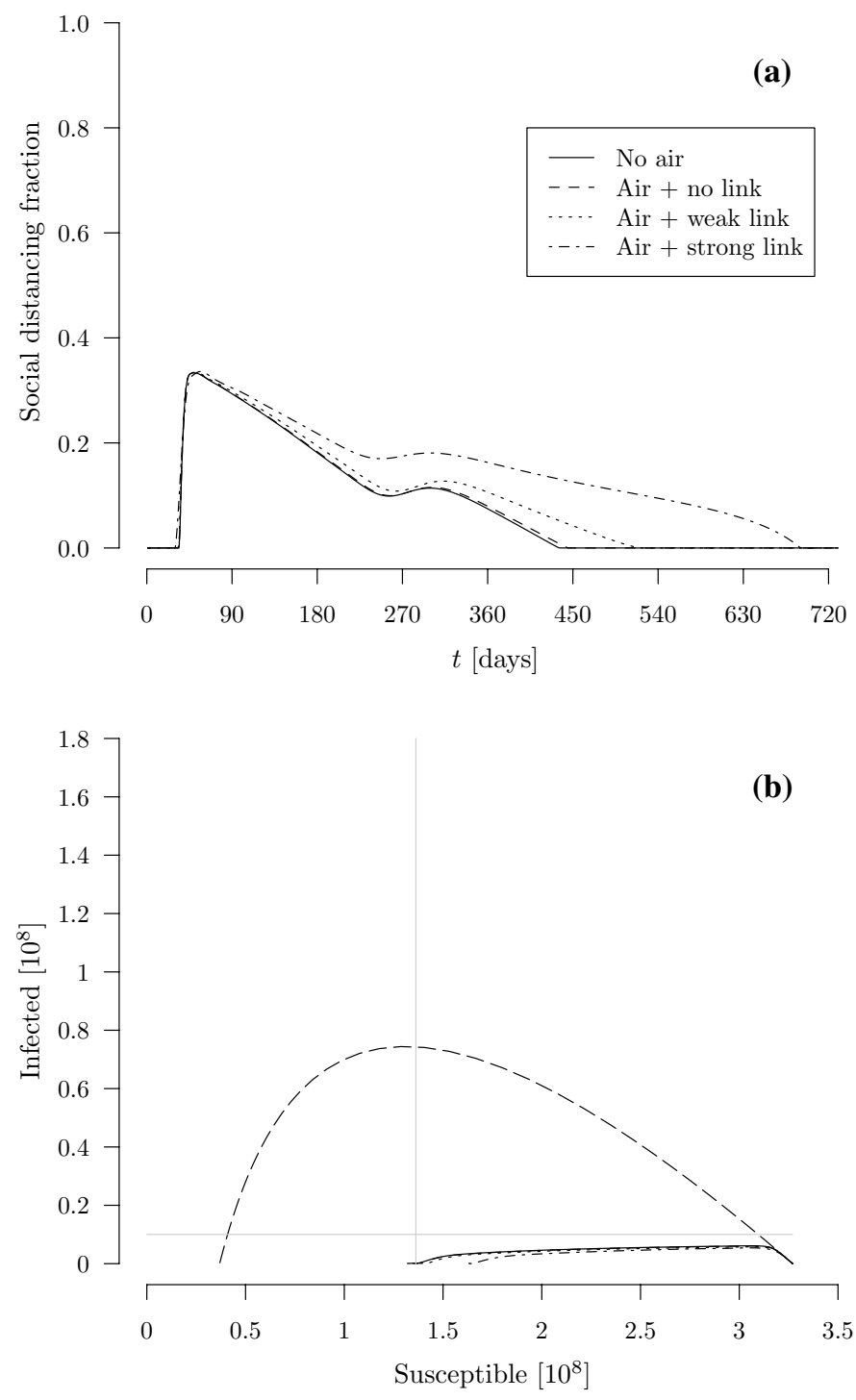

Fig. 2 Optimal control path (a) and $S-I$ phase diagram (b) given $R_{0}=2.4, V S L=10^{7}, \theta=0.5$, and $\tilde{I}=10^{7}$

40 million, which is the number of people who would avoid infection in this uncontrolled scenario.

In all four air pollution variations, the optimal policies shown in panel (a) are initiated with an abrupt increase in the distancing fraction just in time to arrest the early rapid spread of the pathogen and prevent the number of infections from exceeding the critical threshold of the health care system. As $I_{t}$ approaches the threshold, it is optimal to nearly instantaneously increase the physical distancing fraction from 0 to around 0.35 , which in our benchmark case is initiated on day 37. Ignoring air pollution altogether (solid line), 

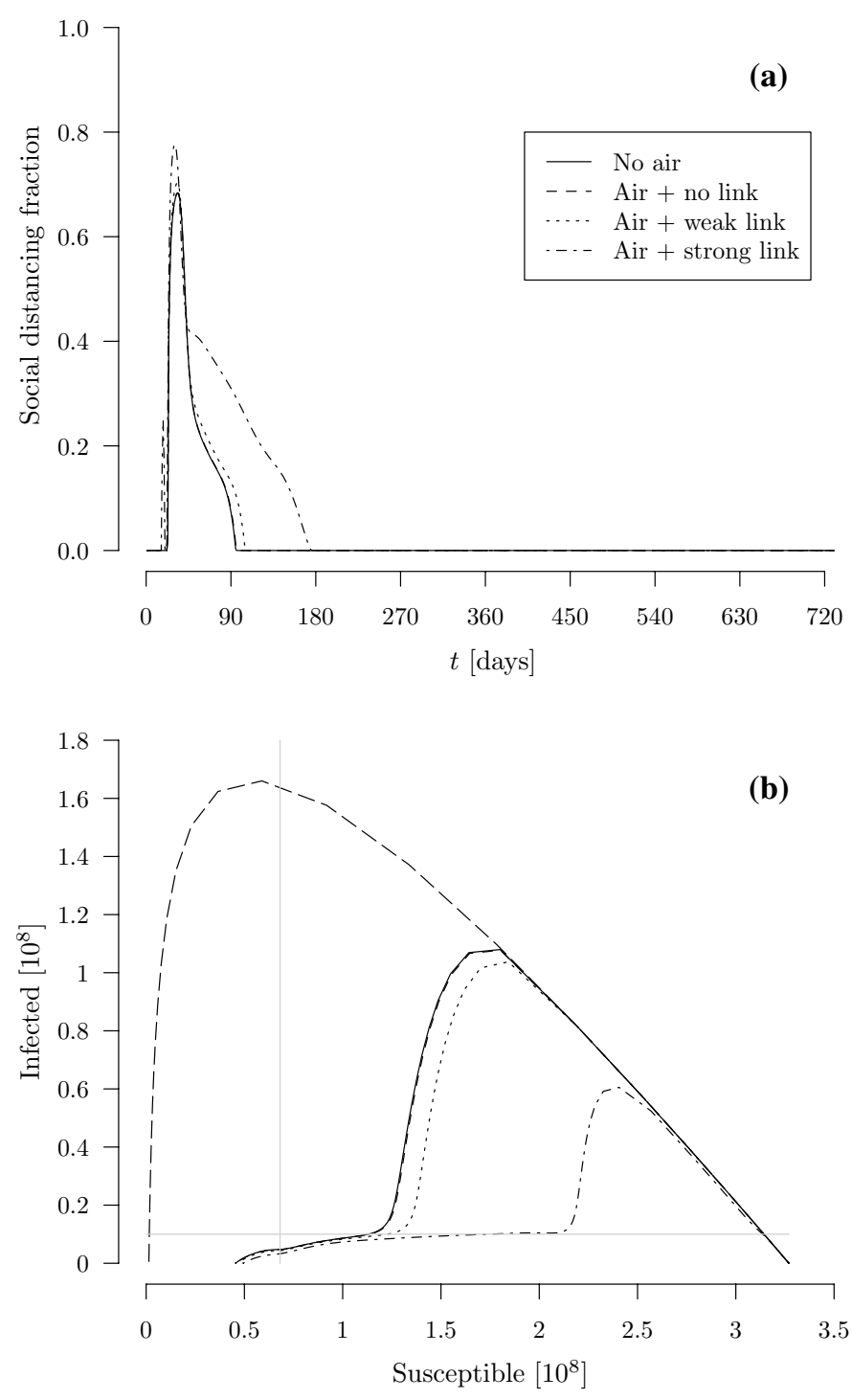

Fig. 3 Optimal control path (a) and $S-I$ phase diagram (b) given $R_{0}=4.8, V S L=4.5 \cdot 10^{6}, \theta=1$, and $\tilde{I}=10^{7}$

after the immediate rapid increase the physical distancing fraction is then reduced nearly linearly until around day 210. The policy then increases again, modestly and temporarily, before finally decreasing to zero by day 289. At the other extreme, when air pollution co-benefits and a strong link between pollution and COVID-19 deaths are included (dotdashed line), the policy begins with nearly identical timing and intensity but is maintained at a higher intensity for a longer duration, decreasing to zero by day 380. Qualitatively, the optimal policies in all four air pollution co-benefit variations involve an early rapid increase in the distancing fraction, then a gradual decline over the course of nearly a full year. The 
influence of air pollution co-benefits on the shape of the optimal policy is negligible if no link between pollution and COVID-19 is included, but is prominent if the link is strong.

The horizontal line in panel (b) corresponds to $\tilde{I}$, the inflection point of the case fatality ratio function, and the vertical line corresponds to $N\left(1-1 / R_{0}\right)$, the herd immunity threshold for susceptible individuals. The phase diagram in Fig. 1 shows that all four controls lead to similar $S-I$ curves, each turning down shortly before the critical threshold is reached and extending to just beyond the herd immunity level, which serves to prevent a second wave of infections after physical distancing restrictions are lifted. The rapid increase in the distancing fraction for all variations shown in panel (a) flattens the curve of infections, as shown in panel (b). The general pattern is similar to those found in other optimal control studies, including Alvarez et al. (2020) and Kruse and Strack (2020).

Key outcomes for the benchmark case are provided in the first column of Table 2. Using our benchmark parameters, the uncontrolled outbreak results in just over 4 million COVID-19 deaths. This is a result of nearly 300 million cases of infection and the elevated case fatality ratio due to the critical threshold of the health care system being exceeded for a large portion of the duration of the uncontrolled outbreak. The controlled scenarios all save nearly 2.5 million lives or more relative to a no-distancing scenario, depending on the influence of air pollution in each variation. When air pollution co-benefits are excluded altogether, 2.47 million COVID-19 deaths are averted by physical distancing, which also leads to an initial decline in GDP of nearly 5.95 percent.

When air pollution co-benefits are included but with no link between air pollution and COVID-19 deaths, the control policy becomes slightly more stringent, as indicated by the slightly larger immediate decline in GDP of 5.98 percent. In addition to the 2.47 million COVID-19 deaths averted, 6,540 air pollution deaths due are averted due to the temporarily reduced levels of $\mathrm{PM}_{2.5}$ during the period of physical distancing. This is roughly 6 percent of the baseline air pollution deaths $(107,000)$, so the lives saved from air pollution are roughly proportional to the immediate decline in GDP.

In the third variation, which includes a weak link between air pollution and COVID-19 deaths $(v=0.077$, based on Wu et al. 2020), the control policy is now discernably altered from the "no air pollution" variation. With a weak link, 2.55 million COVID-19 deaths are averted, which includes an additional 60,000 averted deaths due to the interaction between air pollution and the COVID-19 fatality risk. This is nearly ten times larger than the 6,760 deaths averted due to the direct effects of air pollution on mortality.

The final variation includes a strong link between air pollution and COVID-19 deaths $(v=0.693$, based on Persico and Johnson 2020). In this case more than 3 million COVID19 deaths are averted, including more than 0.5 million due to the interaction with air pollution, and 8,290 deaths are averted due to the direct effects of air pollution. ${ }^{4}$ The stronger interaction between air pollution and COVID-19 deaths in this variation leads to a control policy that is sustained at a higher stringency and for a longer duration, which in turn leads to a larger immediate decline in GDP of 7.59 percent.

In all four air pollution variations the optimal control policy concludes well before the time horizon of the model, which is 2 years (730 days). This suggests that if a vaccine will not be available before that time, then the vaccine would not affect the optimal physical distancing policy. The vaccine still would be useful in reducing the risk of future infections

\footnotetext{
4 As a point of comparison, Cicala et al. (2020) estimate that during the early phase of the COVID-19 outbreak in the U.S., about 360 of 1,500 expected deaths per month from $\mathrm{PM}_{2.5}$ exposure were averted due to emission reductions from physical distancing.
} 
from imported cases, but it would not be necessary to eliminate the risk of a future outbreak due to community spread because the number of susceptible individuals would have already been decreased below the herd immunity threshold. Childhood vaccinations also might be warranted after this time to prevent the number of susceptible individuals from climbing back above the herd immunity threshold over time as immune individuals die and new cohorts enter the population without immunity. And if infection does not confer lifelong immunity, then the role of a vaccine increases further still.

Results for the second case are shown in Fig. 2 and the second column of Table 2. In this case, all parameters are held at their benchmark values except the curvature of the physical distancing cost function, which is here set to $\theta=0.5$. This implies a concave relationship between interpersonal contacts and income, which means that the first increments of physical distancing, which involves a reduction in the rate of interpersonal contacts, are less costly than later increments. In this case the proportional decline in income is less than the physical distancing fraction. The effect of this assumption is to make physical distancing less costly overall, which leads to an optimal policy that is more stringent and of longer duration than our benchmark case, as shown in panel (a) of Fig. 2. Here the control policies start around day 31 and conclude between days 437 and 692. With a less costly physical distancing technology, the influence of including air pollution co-benefits is more pronounced. Even the variation with no interaction between pollution and COVID-19 fatalities is discernible in panel (a), and the variations with a weak and strong link extend the duration of the policy roughly 2 months and 7 months, respectively. The quantitative differences in outcomes can be seen in Table 2. When air pollution co-benefits are excluded entirely, more COVID-19 deaths are averted (2.65 million) at a lower immediate decline in GDP (4.49 percent) relative to our benchmark case in column 1. Accounting for air pollution co-benefits reveals that an additional 9,410 deaths are averted due to reduced air pollution exposure, but otherwise the outcomes are nearly identical to the no air pollution variation. Assuming a weak link between air pollution and COVID-19 deaths, the policy adjusts to avert 2.79 million COVID-19 deaths, which includes 81,000 deaths averted due to the interaction with air pollution. Assuming a strong link with air pollution leads to a dramatic increase in the duration of the policy and the number of deaths averted for about the same cost as in the benchmark case, as reflected in the nearly equivalent immediate GDP decline of 7.6 percent. In addition, given the increased stringency and duration of the program, the relative influence of air pollution co-benefits is magnified. Panel (a) in Fig. 2 demonstrates the significant difference in optimal physical distancing with and without air pollution cobenefits, and the cumulative numbers of pollution deaths averted increases significantly. While total costs in this case increase, the increased numbers of deaths avoided more than compensates and therefore extends the duration of physical distancing measures. By comparison to our benchmark case, these results suggest that large gains in efficiency could be achieved if the cost heterogeneity of component physical distancing measures is high, and if we are able to deploy the component measures in decreasing order of their cost-effectiveness (Newell and Stavins 2003).

Results for the third and final case we examine in this paper are shown in Fig. 3 and the third column of Table 2 . In this case we vary two parameters: $R_{0}$ is increased to 4.8 [closer to the estimate reported by Sanche et al. (2020)], and VSL is decreased to $\$ 4.5$ million [to match the average value used by Greenstone and Nigam (2020)]. The optimal control policies and associated outcomes are qualitatively different in this case. Relative to our first two cases, here the optimal policy rapidly increases to a much higher level of stringencybetween 0.7 and 0.8 - but is sustained for a much shorter duration-between about 90 and 180 days. As a result, the curve of infections is not immediately flattened as in cases 1 and 
2. In this case, it is optimal to let infections exceed the medical system threshold before initiating physical distancing. Infections are allowed to grow past 100 million in the variation with no air pollution co-benefits, and past 60 million in the variation with a strong link between infection fatality risk and air pollution. When physical distancing restrictions are initiated, the high stringency of the measures quickly reduces the number of infections back below the medical system threshold. Thereafter, physical distancing measures are gradually released until herd immunity is achieved. When air pollution co-benefits are included and a strong link between pollution and COVID-19 deaths is assumed, the peak of infections under the optimal control policy is just over one third of the uncontrolled peak. Here again we see that a strong link between pollution and COVID-19 deaths has a large influence on the shape of the optimal control policy, but even in this variation the curve of infections is not completely flattened below the critical threshold of the health care system. The optimal policy fails to flatten the curve in this case for two reasons. The obvious reason is that with a lower VSL the demand for saving lives is lowered. Assigning a lower value to mortality risks reduces the implied damage to society from the outbreak and results in reduced net benefits of the control policy. The less obvious reason is that with a higher $R_{0}$, physical distancing is less effective at stemming the spread of the virus: reducing $R_{0}$ from a very high level to a high level prevents fewer infections than reducing $R_{0}$ from a high level to a medium level (Thunström et al. 2020). These two effects combine to yield an optimal policy that allows a much larger number of deaths than cases 1 and 2. (In other cases not reported here, we found that the infection curve is flattened with $R_{0}=4.8$ and VSL $=\$ 10$ million, and is nearly flattened with $V S L=\$ 4.5$ million and $R_{0}=2.4$.)

\section{Discussion}

Physical distancing has so far been the most widely used policy to control the spread of SARS-CoV-2. While the benefits to physical distancing are large, given the substantial number of lives saved, such measures also impose significant private and social costs. In this study we characterized the intensity and timing of physical distancing that minimizes total economic damages from controlling COVID-19, and we examined the co-benefits of lives saved from air pollution and a potential link between air pollution and COVID-19 fatalities.

Our model jointly considers physical distancing that results from policies (mandates or recommendations) and individual decisions to self-protect, independent of policies. Benefits from physical distancing are recorded as lives saved, while costs are measured as the loss of income in both the short run (during the period of physical distancing) and the long run (as the economy recovers from the initial shock). On the benefit side, lives saved result both from averted COVID-19 deaths and averted air pollution deaths. In our integrated epidemiological-economic model of COVID-19 in the U.S., deploying a physical distancing policy with optimal timing and intensity saves millions of lives and generates significant net benefits in comparison to an uncontrolled scenario with no physical distancing. We also find that thousands more deaths are averted due to the reduction of air pollution emissions from physical distancing, and hundreds of thousands more COVID-19 deaths are averted if we assume a strong causal link between air pollution concentrations and the COVID-19 fatality risk, which is suggested by some preliminary evidence of this association.

More than 4 million deaths from infection are predicted in the uncontrolled scenarios, and even in the optimally controlled scenarios more than 1 million deaths are predicted. To 

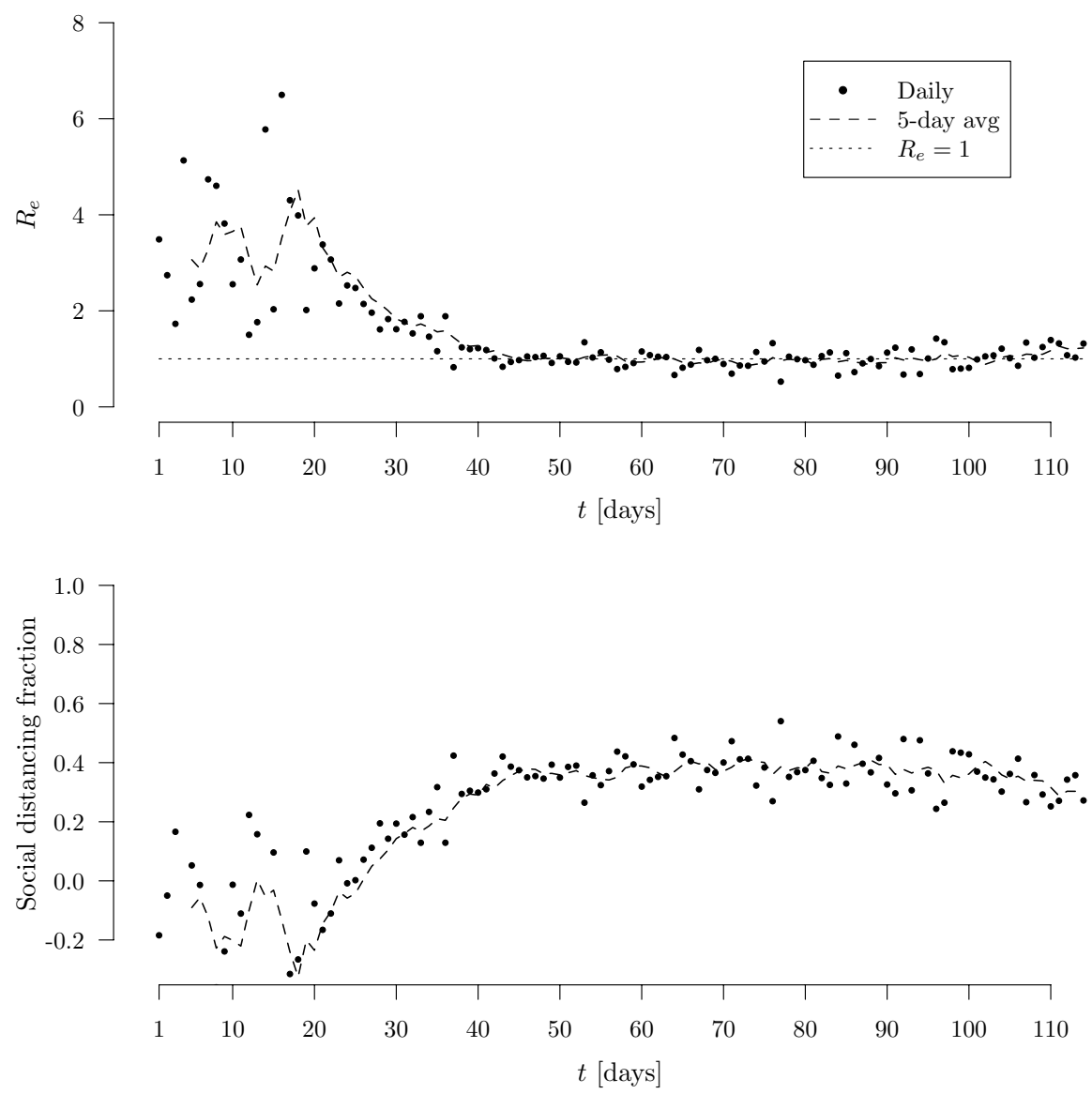

Fig. 4 Daily and 5-day running average effective reproduction number, $R_{e}$ (top), and physical distancing fraction, $x$ (bottom), in the United States between March 1 and June 23, 2020, imputed from cumulative cases of infections reported by the Centers for Disease Control and Prevention as described in the "Appendix"

provide some context for these results, Fig. 4 shows the imputed time path of the effective reproduction number, $R_{e}$, which is proportional to the contact rate as it changes over the course of the outbreak (Aronson et al. 2020), and the physical distancing fraction, $x_{t}$, From March 1 through June 23, 2020 in the United States. The graphs are based on U.S. Centers for Disease Control and Prevention (CDC) reports of the cumulative number of infections (CDC 2020), assuming that the spread of the virus evolves according to an SIR model similar to the one used in our optimal control scenarios (see the "Appendix" for details). The imputed effective reproduction numbers, shown in the top panel of the figure, are between 2 and 7 during the early weeks of March, then trend down to around 1 by the second half of April. The implied physical distancing fractions, shown in the bottom panel of the figure, increase from close to zero at the beginning of the time window to around 0.35 during the latter half of the time window. In comparison to the uncontrolled $S-I$ curves shown in panel (b) of Fig. 1, the observed time series of cases and the imputed $R_{e}$ values suggest that physical distancing measures in the U.S. have been sufficient to dramatically reduce 
the number of infections and deaths relative to a counter-factual scenario with no physical distancing. 5

Compared to the number of cases so far reported in the U.S., which provide the basis of the graphs shown in Fig. 4, the optimal control paths shown in Figures 1, 2, and 3 allow a much larger number of infections to accumulate early in the outbreak before the rapid escalation of physical distancing [consistent with other recent studies, e.g. Alvarez et al. (2020) and Kruse and Strack (2020)]. This strategy provides a head start on achieving herd immunity while still preventing the number of people who are infected at any one time to exceed the critical threshold of the health care system. If aggressive physical distancing measures are implemented before many infections have occurred and are maintained at a sufficiently high intensity to keep the number of infections very low over time, then when physical distancing measures are relaxed a second wave of infections will occur because the number of susceptible individuals would still be very high. At least two categories of control options not considered here could change the character of this result. Either the widespread use of cloth masks (Eikenberry et al. 2020; Howard et al. 2020), or a program of diagnostic testing and self-quarantine (Piguillem and Shi 2020; Taipale et al. 2020; Allen et al. 2020), or a combination of these, might allow the relaxation of physical distancing and avoid a second wave of infections while awaiting the development of a vaccine or effective treatment. If a vaccine or treatment were to become available before the optimal distancing policies in Figs. 1, 2, and 3 are concluded, then a higher intensity and shorter duration physical distancing policy may be optimal. Cloth masks and testing and self-isolation measures might also serve as effective substitutes for physical distancing restrictions at all stages of an outbreak, so incorporating these additional control measures into our model would be a useful extension in follow-up work.

Several other limitations of our model also should be highlighted. First, we value only the reduction in the fatality risks from infection to the exclusion of all other adverse health outcomes short of death. In benefit-cost studies of environmental regulations, fatality risk reductions typically comprise 90 percent or more of the monetized health benefits (e.g. Cropper et al. 2011), but it is not clear whether this will apply to COVID-19 cases. Second, the narrow peaks of the infection curves in Figs. 1, 2, and 3 are characteristic of a single well mixed population. In reality, the U.S. may be better represented as many connected population centers in a spatially explicit model of disease spread, which could produce a series of overlapping and interacting infection curves more closely matching the observed patterns of cases (Unwin et al. 2020). We also do not distinguish between individuals of different ages or pre-existing health conditions that may make them more vulnerable to COVID-19 (Acemoglu et al. 2020), nor do we distinguish between symptomatic and asymptomatic cases (Stock 2020). We also do not model the un-coordinated physical distancing responses of individuals in an unregulated scenario. Rather, we compare the optimal physical distancing policy to a completely uncontrolled epidemic, in which individuals engage in no self-protective behaviors. (As might occur if COVID-19 were widely but erroneously viewed as no more dangerous than the seasonal flu.) Standard economic theory predicts that if the true risks are known then people would choose to distance themselves to a degree that their individual net benefits are maximized (Toxvaerd 2020). With high enough infection and fatality risks, we would expect some voluntary physical distancing,

\footnotetext{
5 Another factor that we do not examine here but may be important for interpreting the observed number of cases over time and for estimating the case fatality ratio is the unknown share of asymptomatic cases of infections that remain unrecorded (Stock 2020).
} 
but generally less than the economically efficient level. Because our net benefit estimates presented in Table 2 are calculated with respect to a no-physical distancing counterfactual scenario, they provide an upper bound on the net benefits of externally imposed physical distancing restrictions. We also ignore a number of other potentially important side-effects of physical distancing, which may include increased incidence of domestic abuse as families spend more time at home (van Gelder et al. 2020), increased fatality rates from other adverse health conditions as people delay treatment to avoid infection in hospitals (Lazzerini et al. 2020), reductions in crime rates (Mohler et al. 2020), adverse mental health effects of school closures (Lee 2020), and increased rates of suicide due to social isolation (Gunnell et al. 2020). Finally, we focus on economic efficiency and do not address the equity implications of the disease risks or the economic effects of physical distancing. Like for COVID-19 related deaths, the adverse health effects of air pollution are asymmetrical across race and income (e.g. Bowe et al. 2019), and we would expect the economic costs of physical distancing also to be borne disproportionately by marginalized groups and low income households.

To conclude, we discuss some potential environmental implications of the pandemic beyond the links between COVID-19, physical distancing, and air pollution examined in our optimal control model. Our aim in this closing section is two-fold: to acknowledge the narrow focus of our control model, and to highlight opportunities for further research by environmental economists going forward. Our brief discussion here is complementary to Helm (2020), IGES (2020), and Barbier (2020), who provide broader discussions of the potential long-run environmental impacts from COVID-19. A key question highlighted by these articles is whether the necessary fiscal stimulus implemented to accelerate the economic recovery will have the effect of re-entrenching the status quo or helping societies "build back better" by improving economic resilience and environmental quality in tandem.

We organize our closing discussion by considering possible long-run changes in how people will work, rest, eat, and play after COVID-19. First, among the most important components of physical distancing measures widely adopted during the early months of the pandemic are work-from-home policies, reduced international and domestic travel for in-person meetings, and distance education. To the extent that technical change involves learning by doing, this could lower the cost and thereby increase the long-run prevalence of remote work and online learning. This could in turn reduce polluting emissions from ground and air traffic and make durable a portion of the short-run decline in emissions observed in the early days of the pandemic, thereby slowing the rate of climate change and reducing the incidence of adverse health effects due to pollution. COVID-19 also could accelerate the contraction of globalization, reducing the trade of goods and services and the movement of people among nations. This re-animates a large literature on the impacts of globalization on the environment (Boyce 2004; Gallagher 2009). Another possibility, likely to vary considerably among nations, is that the cost of economic recovery could crowd-out existing environmental regulations. If there is a de facto constraint on the overall size and scope of government regulations in a country, then an expanded role for government in the provision of public health may lead to a diminished role in the provision of environmental protection. Closer to home for readers of scholarly journals like this one, we wonder about the implications of this episode for the conduct of economic research and science communication, including the publication and promotion through popular media of rapid results prior to formal peer review. We see pros and cons of the current emergency response by academics to the pandemic. Rapid dissemination of pre-prints may allow for more timely and actionable science to reach the decision-makers who need it, but also might lead to a 
higher rate of false results (e.g. Freedman 2020; Joseph 2020; Majumder and Mandl 2020). Striking the right balance between false positives and false negatives in published results during normal times is a complicated (and we think understudied) problem, and it is not clear whether and how the balance should change in times of a public health crisis like COVID-19.

Second, will COVID-19 have a lasting influence on where people choose to rest- that is, where they choose to live? If large cities are engines of economic growth-a conventional but not a consensus view (e.g. Annez and Buckley 2009; Parkinson et al. 2015; Frick and Rodríguez-Pose 2018)—but also come be known as engines of infectious disease outbreaks (Stier et al. 2020), what are the implications for the optimal spatial patterns of human settlements? Any such influence would have important long-run implications for the environment (Newman 2006). For example, if the COVID-19 pandemic helps to slow or reverse the trend of migration from rural areas to urban centers in the U.S. (Harris Poll 2020), this would in turn change the overall amount and the spatial pattern of pollution and habitat loss. If compact human settlements are better for biodiversity, then a reversal of the trend toward agglomeration in urban centers could have adverse effects on nature and the provision of valuable ecosystem services. This would increase the importance of learning how to design dispersed human settlements that are closely connected to nature with minimal environmental impact, rather than reducing impact by concentrating human settlements into smaller areas.

Third, will COVID-19 have long-run implications for food production and consumption? The pandemic could reduce both the demand and the supply of meat products due to increased concerns about safety on the part of consumers and increased costs of production if stricter safety regulations are imposed on producers. Shifting away from animal to plant based proteins has the potential to significantly reduce impacts on the environment, including carbon dioxide emissions (Tukker et al. 2011). Preferences for domestically produced food also might increase, as the COVID-19 crisis highlights the urgency for securing a sufficient domestic food supply as a means of enhancing the resilience of local economies in the face of heightened risks of pandemics or other large scale disruptions in the future. Whether this will positively or negatively affect land conservation or the climate depends on the policy choices made about the changes to food supply.

Finally, will the pandemic have a lasting influence on how people spend their leisure time? If people become motivated to shift a portion of their time use to outdoor recreation activities - which might pose lower risks of infection than leisure activities indoors or outdoors in large crowds (Rice et al. 2020; Venter et al. 2020; Samuelsson et al. 2020) - this could increase the instrumental value of a clean environment and untrammeled wilderness areas. It also could expand the health benefits from exercise outdoors (Lippi et al. 2020; Mattioli and Ballerini Puviani 2020; Gössling et al. 2020) and the more general well-being benefits from spending time in nature (Bratman et al. 2019; White et al. 2019). On the other hand, if people withdraw from travel both abroad and at home and spend more time indoors watching screens, or if yet another case of a pathogen jumping from an animal species to humans (zoonosis) (Andersen et al. 2020; Berry et al. 2018) makes some people more fearful of close contact with nature, the health benefits of outdoor recreation might contract rather than expand.

The results from our control model presented in this paper suggest that there may be important environmental side-effects that could alter the optimal intensity and duration of physical distancing policies used to manage the COVID-19 epidemic. Many interventions designed to affect consumer behaviors have been shown to work in the short run, but people typically revert back to their prior behaviors after the intervention is removed (e.g. Nisa 
et al. 2019). So the safe bet may be that the salutary environmental side-effects of physical distancing will dissipate as fast as economic activity resumes after the outbreak. On the other hand, some past public health crises have led to lasting and high-impact changes in behaviors. These include long distance migrations in the United States during the 19th century to escape unhealthy living conditions in eastern cities (Baur 1959; Abrams 2010), and improved personal and public hygiene practices that today we take for granted such as regular health care visits and hand washing habits (Agüero and Beleche 2017; Foss 2020). If COVID-19 leads to behavioral changes as durable as those spurred by past epidemics, the environmental implications of the outbreak may extend far beyond the short-term air pollution impacts examined here.

\section{Appendix}

To produce the graphs in Fig. 4 of the main text, we assumed that the spread of the virus evolved according to an SIR model with an effective contact rate that varies over time with changes in physical distancing . Referring back to equations (1)-(4), the effective contact rate on day $t$ is $\beta_{t}=\left(1-x_{t}\right)^{2} \beta$, and the number of new infections on day $t$ is $\beta_{t} S_{t} I_{t}$, where $\beta$ is the contact rate with no physical distancing, and $x_{t}$ is the distancing fraction on day $t$. The U.S. Centers for Disease Control and Prevention (CDC) reports the cumulative number of infections since January 22, 2020 (CDC 2020). Denoting the cumulative number of infections reported prior to day $t$ as $C_{t}$, we can write $C_{t+1}-C_{t}=\beta_{t} S_{t} I_{t}$. Ignoring deaths for simplicity, this leads to the following sequential procedure for imputing $\beta_{t}, R_{e, t}$, and $x_{t}$ based on the reported values for $C_{t}$ and an assumed value of $\gamma$ :

$$
\begin{aligned}
& \begin{array}{l}
I_{1}=C_{1}, S_{1}=N-C_{1} \\
\text { for } t=1 \text { to } T-1 \\
\quad \beta_{t}=\left(C_{t+1}-C_{t}\right) /\left(S_{t} I_{t}\right) \\
R_{e, t}=\beta_{t} S_{t} / \gamma \\
\quad x_{t}=1-\sqrt{\beta_{t} / \beta_{1}} \\
\quad S_{t+1}=S_{t}-\beta_{t} S_{t} I_{t} \\
\quad I_{t+1}=I_{t}+\beta_{t} S_{t} I_{t}-\gamma I_{t}
\end{array} \\
& \text { end }
\end{aligned}
$$

\section{References}

Abel T, McQueen D (2020) The COVID-19 pandemic calls for spatial distancing and social closeness: not for social distancing!. Int J Public Health 65(3):231

Abrams J (2010) On the road again: consumptives traveling for health in the American West, 1940-1925. Great Plains Q 30(4):271-285

Acemoglu D, Chernozhukov V, Werning I, Whinston MD (2020) A multi-risk SIR Model with optimally targeted lockdown. Technical report. National Bureau of Economic Research (NBER) Working Paper No. 27102

Agüero JM, Beleche T (2017) Health shocks and their long-lasting impact on health behaviors: evidence from the $2009 \mathrm{H} 1 \mathrm{~N} 1$ pandemic in Mexico. J Health Econ 54:40-55

Allen D, Block S, Cohen J, et al (2020) Roadmap to pandemic resilience: massive scale testing, tracing, and supported isolation (TTSI) as the path to pandemic resilience for a free society. Safra Center 
for Ethics at Harvard University, 20. https://ethics. harvard. edu/files/center-for-ethics/files/ roadmaptopandemicresilience_updated_4

Alvarez FE, Argente D, Lippi F (2020) A simple planning problem for covid-19 lockdown. National Bureau of Economic Research (NBER) Working Paper No. 26981

American Hospital Association (2020). Fast Facts on U.S. Hospitals, 2020. https://www.aha.org/statistics/ fast-facts-us-hospitals (visited: 2020-05-02)

Andersen KG, Rambaut A, Lipkin WI, Holmes EC, Garry RF (2020) The proximal origin of SARS-CoV-2. Nat Med 26(4):450-452

Annez PC, Buckley RM (2009) Urbanization and growth: setting the context. Urban Growth 1:1-45

Aronson, J. K., Brassey, J., and Mahtani, K. R. (2020). "When will it be over?": An introduction to viral reproduction numbers, $\mathrm{R}_{0}$ and $\mathrm{R}_{e}$. https://www.cebm.net/wp-content/uploads/2020/04/When-will-itbe-over-An-introduction-to-viral-reproduction-numbers-1.pdf (visited: 2020-05-02)

Barbier EB (2020) Greening the post-pandemic recovery in the G20. Environ Resour Econ, pp 1-19. https:// doi.org/10.1007/s10640-020-00437-w

Baur JE (1959) The health seeker in the westward movement, 1830-1900. Miss Valley Hist Rev 46(1):91-110

Berry K, Bayham J, Meyer SR, Fenichel EP (2018) The allocation of time and risk of Lyme: a case of ecosystem service income and substitution effects. Environ Resour Econ 70(3):631-650

Bertsekas DP (2015) Value and policy iterations in optimal control and adaptive dynamic programming. IEEE Trans Neural Netw Learn Syst 28(3):500-509

Bolzoni L, Bonacini E, Della Marca R, Groppi M (2019) Optimal control of epidemic size and duration with limited resources. Math Biosci 315:108232

Bowe B, Xie Y, Yan Y, Al-Aly Z (2019) Burden of cause-specific mortality associated with pm2.5 air pollution in the united states. JAMA Netw Open 2(11):e1915834-e1915834

Boyce JK (2004) Green and brown? Globalization and the environment. Oxford Rev Econ Policy 20(1):105-128

Bratman GN, Anderson CB, Berman MG, Cochran B, De Vries S, Flanders J, Folke C, Frumkin H, Gross JJ, Hartig T et al (2019) Nature and mental health: an ecosystem service perspective. Sci Adv 5(7):eaax0903

Burnett R, Chen H, Szyszkowicz M, Fann N, Hubbell B, Pope CA, Apte JS, Brauer M, Cohen A, Weichenthal S et al (2018) Global estimates of mortality associated with long-term exposure to outdoor fine particulate matter. Proc Natl Acad Sci 115(38):9592-9597

Cameron TA (2010) Euthanizing the value of a statistical life. Rev Environ Econ Policy 4(2):161-178

CDC (2020) Coronavirus Disease 2019 (COVID-19): cases in the U.S. https://www.cdc.gov/coronaviru s/2019-ncov/cases-updates/cases-in-us.html (visited 2020-04-26)

Cicala S, Holland SP, Mansur ET, Muller NZ, Yates AJ (2020) Expected health effects of reduced air pollution from COVID-19 social distancing. National Bureau of Economic Research (NBER) Working Paper No. 27135

Cox DR (1972) Regression models and life-tables. J R Stat Soc: Ser B (Methodological) 34(2):187-202

Cropper M, Hammitt JK, Robinson LA (2011) Valuing mortality risk reductions: progress and challenges. Annu Rev Resour Econ 3(1):313-336

di Toppi LS, di Toppi LS, Bellini E et al (2020) Novel coronavirus: how atmospheric particulate affects our environment and health. Challenges 11(1):1-12

Dorigatti I, Okell L, Cori A, Imai N, Baguelin M, Bhatia S, Boonyasiri A, Cucunubá Z, Cuomo-Dannenburg G, FitzJohn R, et al (2020) Report 4: severity of 2019-novel coronavirus (nCoV). Imperial College London (10-02-2020). https://doi.org/10.25561/77154

Eichenbaum MS, Rebelo S,Trabandt M (2020) The macroeconomics of epidemics. National Bureau of Economic Research (NBER) Working Paper No. 26882

Eikenberry SE, Mancuso M, Iboi E, Phan T, Eikenberry K, Kuang Y, Kostelich E, Gumel AB (2020) To mask or not to mask: modeling the potential for face mask use by the general public to curtail the COVID-19 pandemic. Infect Dis Model 5:293-308

Evans MF, Smith VK (2006) Do we really understand the age-VSL relationship? Resour Energy Econ 28(3):242-261

Farboodi M, Jarosch G, Shimer R (2020) Internal and external effects of social distancing in a pandemic. National Bureau of Economic Research (NBER) Working Paper No. 27059

Fenichel EP (2013) Economic considerations for social distancing and behavioral based policies during an epidemic. J Health Econ 32(2):440-451

Fenichel EP, Castillo-Chavez C, Ceddia MG, Chowell G, Parra PAG, Hickling GJ, Holloway G, Horan R, Morin B, Perrings C et al (2011) Adaptive human behavior in epidemiological models. Proc Nat Acad Sci 108(15):6306-6311 
Ferguson N, Laydon D, Nedjati Gilani G, Imai N, Ainslie K, Baguelin M, Bhatia S, Boonyasiri A, Cucunuba Perez Z, Cuomo-Dannenburg G, et al (2020) Report 9: impact of non-pharmaceutical interventions (NPIs) to reduce COVID19 mortality and healthcare demand (2020). Imperial College, London

Foss KA (2020) How epidemics shaped modern life. https://www.zocalopublicsquare.org/2020/04/01/whatwe-can-learn-from-epidemics-covid-19-tuberculosis/ideas/essay/. Accessed 23 May 2020

Freedman DH (2020) A prophet of scientific rigor-and a covid contrarian. Wired. https://www.wired.com/ story/prophet-of-scientific-rigor-and-a-covid-contrarian/. Accessed 22 May 2020

Frick SA, Rodríguez-Pose A (2018) Big or small cities? On city size and economic growth. Growth Change 49(1):4-32

Gallagher KP (2009) Economic globalization and the environment. Annu Rev Environ Resour 34:279-304

Gersovitz M (2011) The economics of infection control. Annu Rev Resour Econ 3(1):277-296

Gersovitz M, Hammer JS (2004) The economical control of infectious diseases. Econ J 114(492):1-27

Sachs G (2020) Bear essentials: a guide to navigating a bear market. https:/www.goldmansachs.com/insig hts/pages/briefly/bear-essentials.pdf (visited: 2020-05-02)

Gonzalez-Eiras M, Niepelt D (2020) On the optimal 'lockdown' during an epidemic. In: CESifo working paper

Goodkind AL, Tessum CW, Coggins JS, Hill JD, Marshall JD (2019) Fine-scale damage estimates of particulate matter air pollution reveal opportunities for location-specific mitigation of emissions. Proc Natl Acad Sci 116(18):8775-8780

Gössling S, Scott D, Hall CM (2020) Pandemics, tourism and global change: a rapid assessment of COVID19. J Sustain Tour. https://doi.org/10.1080/09669582.2020.1758708

Greenstone M, Nigam V (2020) Does social distancing matter? University of Chicago, Becker Friedman Institute for Economics Working Paper No. 2020-26

Gunnell D, Appleby L, Arensman E, Hawton K, John A, Kapur N, Khan M, O'Connor RC, Pirkis J, Caine ED, et al (2020) Suicide risk and prevention during the COVID-19 pandemic. Lancet Psychiatry. https://doi.org/10.1016/S2215-0366(20)30171-1

Hall RE, Jones CI, Klenow PJ (2020) Trading off consumption and COVID-19 deaths. Technical report. http://klenow.com/Consumption_vs_COVID19.pdf. Accessed 25 May 2020

Hammitt JK (2007) Valuing changes in mortality risk: lives saved versus life years saved. Rev Environ Econ Policy 1(2):228-240

Hansen E, Day T (2011) Optimal control of epidemics with limited resources. J Math Biol 62(3):423-451

Harrell FE Jr (2015) Regression modeling strategies: with applications to linear models, logistic and ordinal regression, and survival analysis. Springer, Berlin

Harris Poll (2020) Amid the COVID-19 pandemic, urbanites are eyeing the suburbs. https://theharrispoll. com/survey-amid-the-covid-19-pandemic-urbanites-are-eyeing-the-suburbs/. Accessed 23 May 2020

Helm D (2020) The environmental impacts of the coronavirus. Environ Resour Econ. https://doi. org/10.1007/s10640-020-00426-z

Hethcote HW (1989) Three basic epidemiological models. In: Applied mathematical ecology. Springer, Berlin, pp 119-144

Howard J, Huang A, Li Z, Tufekci Z, Zdimal V, van der Westhuizen H, von Delft A, Price A, Fridman L, Tang L-H, Tang V, Watson GL, Bax CE, Shaikh R, Questier F, Hernandez D, Chu LF, Ramirez CM, Rimoin AW (2020) Face masks against COVID-19: an evidence review. Preprints. 2020040203. https ://doi.org/10.20944/preprints202004.0203.v1

IEA (2020). Global Energy Review 2020. https://www.iea.org/reports/global-energy-review-2020.Accessed 02 May 2020

IGES (2020). Implications of COVID-19 for the environment and sustainability. Institute for Global Environmental Strategies. https://www.iges.or.jp/en/news/20200514

Joseph A (2020) Lancet, New England Journal retract Covid-19 studies, including one that raised safety concerns about malaria drugs. https://www.statnews.com/2020/06/04/lancet-retracts-major-covid-19paper-that-raised-safety-concerns-about-malaria-drugs/

Keeling MJ, Rohani P (2011) Modeling infectious diseases in humans and animals. Princeton University Press, Princeton

Kermack WO, McKendrick AG (1927) A contribution to the mathematical theory of epidemics. In: Proceedings of the Royal Society of London. Series A, Containing papers of a mathematical and physical character, 115(772), 700-721

Kniesner TJ, Viscusi WK (2019) The value of a statistical life. Oxford Research Encyclopedia of Economics and Finance

Kniesner TJ, Viscusi WK, Ziliak JP (2006) Life-cycle consumption and the age-adjusted value of life. BE J Econ Anal Policy 5(1):Article 4 
Kruse T, Strack P (2020) Optimal control of an epidemic through social distancing. Cowles Foundation Discussion Paper. https://papers.ssrn.com/sol3/papers.cfm?abstract_id=3583186

Lauer SA, Grantz KH, Bi Q, Jones FK, Zheng Q, Meredith HR, Azman AS, Reich NG, Lessler J (2020) The incubation period of coronavirus disease 2019 (COVID-19) from publicly reported confirmed cases: estimation and application. Ann Intern Med 172(9):577-582

Lazzerini M, Barbi E, Apicella A, Marchetti F, Cardinale F, Trobia G (2020) Delayed access or provision of care in Italy resulting from fear of COVID-19. Lancet Child Adolescent Health 4(5):e10-e11

Lee J (2020) Mental health effects of school closures during COVID-19. The Lancet. Child \& Adolescent Health. https://doi.org/10.1016/S2352-4642(20)30128-0

Lee S, Chowell G, Castillo-Chávez C (2010) Optimal control for pandemic influenza: the role of limited antiviral treatment and isolation. J Theor Biol 265(2):136-150

Lippi G, Henry BM, Sanchis-Gomar F (2020) Physical inactivity and cardiovascular disease at the time of coronavirus disease 2019 (COVID-19). Eur J Prev Cardiol. https://doi.org/10.1177/2047487320 916823

Liu Y, Gayle A, Wilder-Smith A, Rocklöv J (2020) The reproductive number of COVID-19 is higher compared to SARS coronavirus. J Travel Med 27(2). https://doi.org/10.1093/jtm/taaa021

Majumder MS, Mandl KD (2020) Early in the epidemic: impact of preprints on global discourse about COVID-19 transmissibility. Lancet Global Health 8(5):e627-e630

Martelletti L, Martelletti P (2020) Air pollution and the novel Covid-19 disease: a putative disease risk factor. SN Compr Clin Med. https://doi.org/10.1007/s42399-020-00274-4

Mattioli AV, Ballerini Puviani M (2020) COVID-19 pandemic: the effects of quarantine on cardiovascular risk. Eur J Clin Nutr. https://doi.org/10.1038/s41430-020-0646-Z

Mohler G, Bertozzi AL, Carter J, Short MB, Sledge D, Tita GE, Uchida CD, Brantingham PJ (2020) Impact of social distancing during COVID-19 pandemic on crime in Los Angeles and Indianapolis. J Crim Just 68:101692

National Research Council (2008) Estimating mortality risk reduction and economic benefits from controlling ozone air pollution. National Academies Press

Newell RG, Stavins RN (2003) Cost heterogeneity and the potential savings from market-based policies. J Regul Econ 23(1):43-59

Newman P (2006) The environmental impact of cities. Environ Urban 18(2):275-295

Nisa CF, Bélanger JJ, Schumpe BM, Faller DG (2019) Meta-analysis of randomised controlled trials testing behavioural interventions to promote household action on climate change. Nat Commun 10(1):1-13

Ogen Y (2020) Assessing nitrogen dioxide $\left(\mathrm{NO}_{2}\right)$ levels as a contributing factor to the coronavirus (COVID19) fatality rate. Science of the Total Environment, p 138605

Parkinson M, Meegan R, Karecha J (2015) City size and economic performance: is bigger better, small more beautiful or middling marvellous? Eur Plan Stud 23(6):1054-1068

Perrings C, Castillo-Chavez C, Chowell G, Daszak P, Fenichel EP, Finnoff D, Horan RD, Kilpatrick AM, Kinzig AP, Kuminoff NV et al (2014) Merging economics and epidemiology to improve the prediction and management of infectious disease. EcoHealth 11(4):464-475

Persico CL, Johnson KR (2020) Deregulation in a time of pandemic: does pollution increase coronarirus cases or deaths? In: IZA Institute of Labor Economics Discussion Paper Series, DP No, p 13231

Philipson, T. (2016). Economic epidemiology. Palgrave Macmillan, UK, pp 1-4

Piguillem F, Shi L (2020) The optimal COVID-19 quarantine and testing policies. Technical report, Einaudi Institute for Economics and Finance (EIEF)

Pindyck R (2020) Covid-19 and the welfare effects of reducing contagion. National Bureau of Economic Research (NBER) Working Paper No. 27121

Rice WL, Meyer C, Lawhon B, Taff BD, Mateer T, Reigner N, Newman P (2020) The COVID-19 pandemic is changing the way people recreate outdoors: preliminary report on a national survey of outdoor enthusiasts amid the COVID-19 pandemic. https://doi.org/10.31235/osf.io/prnz9

Riou J, Hauser A, Counotte MJ, Althaus CL (2020) Adjusted age-specific case fatality ratio during the COVID-19 epidemic in Hubei, China, January and February 2020. medRxiv

Rowthorn RE, Laxminarayan R, Gilligan CA (2009) Optimal control of epidemics in metapopulations. J R Soc Interface 6(41):1135-1144

Samuelsson K, Barthel S, Colding J, Macassa G, Giusti M (2020) Urban nature as a source of resilience during social distancing amidst the coronavirus pandemic

Sanche S, Lin YT, Xu C, Romero-Severson E, Hengartner N, Ke R (2020) High contagiousness and rapid spread of severe acute respiratory syndrome coronavirus 2. Emerg Infect Dis 26(7)

Setti L, Passarini F, De Gennaro G, Barbieri P, Perrone MG, Piazzalunga A, Borelli M, Palmisani J, Di Gilio A, Piscitelli P, et al (2020) The potential role of particulate matter in the spreading of COVID-19 in Northern Italy: first evidence-based research hypotheses. medRxiv 
Shepard DS, Zeckhauser RJ (1984) Survival versus consumption. Manag Sci 30(4):423-439

Simon NB, Dockins C, Maguire KB, Newbold SC, Krupnick AJ, Taylor LO (2019) What's in a name? A search for alternatives to "VSL". Rev Environ Econ Policy 13(1):155-161

Stier A, Berman M, Bettencourt L (2020) Covid-19 attack rate increases with city size. Mansueto Institute for Urban Innovation Research Paper. https://papers.ssrn.com/sol3/papers.cfm?abstract_id=3564464

Stock JH (2020) Data gaps and the policy response to the novel coronavirus. Covid Econ 1(3):1-11

Taipale J, Romer P, Linnarsson S (2020) Population-scale testing can suppress the spread of COVID-19. medRxiv

Tang S, Yan Q, Shi W, Wang X, Sun X, Yu P, Wu J, Xiao Y (2018) Measuring the impact of air pollution on respiratory infection risk in China. Environ Pollut 232:477-486

Thunström L, Newbold S, Finnoff D, Ashworth M, Shogren JF (2020) The benefits and costs of social distancing to flatten the curve for COVID-19. J Benefit Cost Anal. https://doi.org/10.1017/bca.2020.12

Toxvaerd F (2020) Equilibrium social distancing. Cambridge-INET Working Paper Series (2020/08)

Tukker A, Goldbohm RA, De Koning A, Verheijden M, Kleijn R, Wolf O, Pérez-Domínguez I, RuedaCantuche JM (2011) Environmental impacts of changes to healthier diets in Europe. Ecol Econ 70(10): 1776-1788

Unwin H, Mishra S, Bradley VC, Gandy A, Vollmer M, Mellan T, Coupland H, Ainslie K, Whittaker C, IshHorowicz J, et al. (2020) Report 23: State-level tracking of COVID-19 in the United States. Imperial College COVID-19 Response Team. VERSION 2 (28-05-2020). https://doi.org/10.25561/79231

U.S. Department of Labor (2020) Employment insurance weekly claims. https://www.dol.gov/ui/data.pdf (visited: 2020-05-02)

U.S. Department of Transportation (2016) Guidance on treatment of the economic value of statistical life (VSL) in US Department of Transportation Analyses-2016 Adjustment. https://www.transportation. gov/sites/dot.gov/files/docs/2016RevisedValueofaStatisticalLifeGuidance.pdf

U.S. Environmental Protection Agency (2014) Guidelines for preparing economic analyses. https://www. epa.gov/environmental-economics/guidelines-preparing-economic-analyses

U.S. Office of Management and Budget (2003) Circular A-4: regulatory analysis. https://obamawhitehouse .archives.gov/omb/circulars_a004_a-4/. Accessed 2 May 2020

van Gelder N, Peterman A, Potts A, O'Donnell M, Thompson K, Shah N, Oertelt-Prigione S (2020) COVID-19: reducing the risk of infection might increase the risk of intimate partner violence. EClinicalMedicine 21:100348

Venter Z, Barton D, Figari H, Nowell M et al (2020) Urban nature in a time of crisis: recreational use of green space increases during the COVID-19 outbreak in Oslo. SocArXiv, Norway

Viscusi WK (2018) Pricing lives: guideposts for a safer society. Princeton University Press, Princeton

White MP, Alcock I, Grellier J, Wheeler BW, Hartig T, Warber SL, Bone A, Depledge MH, Fleming LE (2019) Spending at least 120 minutes a week in nature is associated with good health and wellbeing. Sci Rep 9(1):1-11

Wilson N, Kvalsvig A, Barnard LT, Baker MG (2020) Case-fatality risk estimates for COVID-19 calculated by using a lag time for fatality. Emerg Infect Dis 26(6)

World Health Organization (2020a) Air pollution. https://www.who.int/health-topics/air-pollution (visited: 2 May 2020)

World Health Organization (2020b) "Immunity passports" in the context of COVID-29. Scientific Brief 24 April 2020. https://www.who.int/publications-detail/immunity-passports-in-the-context-of-covid-19 (visited: 2020-05-22)

Wu X, Nethery RC, Sabath BM, Braun D, Dominici F (2020) Exposure to air pollution and covid-19 mortality in the united states: a nationwide cross-sectional study. medRxiv

Wu Z, McGoogan JM (2020) Characteristics of and important lessons from the coronavirus disease 2019 (COVID-19) outbreak in China: summary of a report of 72,314 cases from the Chinese Center for Disease Control and Prevention. J Am Med Assoc 323(13):1239-1242

Xu J, Murphy SL, Kochanek KD, Arias E (2018) Mortality in the United States, 2018. https://www.cdc.gov/ nchs/data/databriefs/db355-h.pdf (visited: 2020-05-02)

Yang S, Cao P, Du P, Wu Z, Zhuang Z, Yang L, Yu X, Zhou Q, Feng X, Wang X et al (2020) Early estimation of the case fatality rate of COVID-19 in mainland China: a data-driven analysis. Ann Transl Med $8(4)$

Publisher's Note Springer Nature remains neutral with regard to jurisdictional claims in published maps and institutional affiliations. 